\title{
Mini-tubérculos de batata semente básica produzidos sob parcelamento e doses de nitrogênio em substrato
}

\author{
Carla do C Milagres; Paulo Cezar R Fontes; Mário Puiatti; Laércio J da Silva \\ Universidade Federal de Viçosa, 36570-000 Viçosa-MG; carla.milagres@ufv.br
}

\begin{abstract}
RESUMO
Objetivou-se com este trabalho determinar a produção de mini-tubérculos de batata semente básica em função da dose e do parcelamento do nitrogênio $(\mathrm{N})$ aplicado ao substrato. Os tratamentos foram constituídos por quatro doses de $\mathrm{N}\left(0,115,230,460 \mathrm{mg} \mathrm{L}^{-1}\right.$ de substrato) e por cinco modos de parcelamento das doses (M): M1 [10\% no plantio $+90 \%$ aos 21 dias após a emergência (DAE)]; M2 [10\% no plantio + 3\% diariamente (21 a 51 DAE)]; M3 [50\% no plantio $+50 \%$ aos $21 \mathrm{DAE}]$; M4 [50\% no plantio $+1,6 \%$ diariamente (21 a $51 \mathrm{DAE})$ ]; M5 (100\% no plantio). O experimento foi instalado no delineamento em blocos casualizados, em esquema fatorial 4x5 (doses x modos), com três repetições, na Universidade Federal de Viçosa. As cultivares plantadas foram Atlantic e Opaline, utilizando-se mini-tubérculos da categoria básica. As plantas foram cultivadas em vasos de $3 \mathrm{~L}$, contendo substrato comercial. Aos 25, 35 e 56 DAE foram avaliados o teor (TN) e quantidade de $\mathrm{N}$ na folha (QNA). Na colheita, aos 86 DAE, foram avaliados número e massas fresca e seca de tubérculos. Em ambas as cultivares, na fase inicial de crescimento da planta, nenhuma combinação de tratamentos (dose e modo) influenciou TN. Nas avaliações posteriores, TN aumentou com aumento da dose de N. Nas duas cultivares, QNA não foi afetado pela aplicação diluída das doses de N. Nenhuma combinação de dose e modo de aplicação do fertilizante nitrogenado influenciou o número de tubérculos. Quando houve efeito de dose de N sobre a massa de tubérculos, a dose zero proporcionou o maior valor da massa. A aplicação concentrada de N no momento da tuberização é prejudicial para a planta, pois reduz a massa seca e fresca de tubérculos.
\end{abstract}

Palavras-chave: Solanum tuberosum, nutrição, adubação nitrogenada, substrato.

\begin{abstract}
Yield of basic seed potato minituber depending on nitrogen fertilizer rates and split applications

This study aimed to evaluate the effect of both $\mathrm{N}$ fertilizer rates and split applications on yield of basic class seed potato mini-tubers. Treatments were four $\mathrm{N}$ rates $\left(0,115,230,460 \mathrm{mg} \mathrm{L}^{-1}\right)$ and five split modes: M1 [10\% at planting $+90 \%$ at 21 days after plant emergence (DAE)]; M2 [10\% at planting + 3\% daily (21 to 51 DAE)]; M3 (50\% at planting $+50 \%$ at $21 \mathrm{DAE})$; M4 [50\% at planting $+1.6 \%$ daily (21 to $51 \mathrm{DAE})$ ]; M5 (100\% at planting). The experiment was set up in randomized blocks design in factorial arrangement $4 \times 5$ (rates $\mathrm{x}$ modes), with three replications. We planted the cultivars Atlantic and Opaline, using basic commercial mini-tubers. Plants were grown in $3 \mathrm{~L}$ pots containing commercial substrate. At 25, 35 and 56 DAE we assessed the content (TN) and amount of N (QNA) in the leaf. At harvest, $86 \mathrm{DAE}$, we determined the number of tubers and fresh and dry tubers mass. For both cultivars, in the early stages of plant growth, neither combination of rate and split modes of nitrogen affected the TN. In subsequent evaluations, TN increased with increasing dose of N. In both cultivars, QNA was not affected by application of diluted doses of N. No combination of dose and split mode of nitrogen fertilizer application influenced the number of tubers. When there was effect of $\mathrm{N}$ rate on tuber mass, the zero rates provided the highest value of this variable. The concentrated application of $\mathrm{N}$ at the tuberization time is harmful for the plant because it reduces both dry and fresh tuber masses.
\end{abstract}

Keywords: Solanum tuberosum, nutrition, nitrogen fertilization, substrate.

\section{(Recebido para publicação em 2 de outubro de 2012; aceito em 1 de agosto de 2013)} (Received on October 2, 2012; accepted on August 1, 2013)

$\mathrm{O}$ Brasil é importador de batata-semente certificada para o plantio. Tubérculo-semente da categoria básica tem elevada padronização fitossanitária e normalmente alta qualidade fisiológica além de preço elevado. Em 2010 a batata-semente representou $17 \%$ do custo de produção da cultura (Agrianual, 2011). Uma possibilidade tecnológica e econômica é comprar e plantar batata-semente da categoria básica para a produção de batata-semente das categorias básica e certificada.

Em qualquer sistema de plantio, a adequada nutrição nitrogenada é fator fundamental para o desenvolvimento e produção das culturas, especialmente da batata (Nava et al., 2007). O nitrogênio (N) é um nutriente essencial que estimula o desenvolvimento e o crescimento da planta. Tanto a deficiência quanto o excesso de $\mathrm{N}$ podem prejudicar a produção de tubérculos (Zvomuya et al., 2003; Silva et al., 2007; Coelho et al., 2010).

Dose adequada de nitrogênio variando de 0 a $400 \mathrm{mg} \mathrm{dm}^{-3}$ tem sido encontrada na literatura para a produção de batata em ambiente protegido, em vaso contendo diferentes substratos orgânicos (Silva et al., 2006; Fontes et al., 2008; Moreira, 2008; Sampaio Junior et al., 2008, 2009). Para o cultivo em argila expandida, Coraspe-Leon (2007) usou doses de $\mathrm{N}$ variando de 8,37 a 16,93 $\mathrm{mmol} \mathrm{L}^{-1}$. Moreira (2008) constatou que a dose de $230 \mathrm{mg} \mathrm{dm}^{-3}$ de $\mathrm{N}$ foi a que proporcionou a máxima produção de tubérculos de batata cv. Ágata propagada por mini-tubérculo e cultivada em vaso contendo substrato comercial.

A aplicação de $\mathrm{N}$ é realizada, quase sempre, de forma parcelada. Desde que 
se disponha de índices calibrados, técnica ainda não ajustada e incorporada ao processo de produção de batata, a tomada de decisão sobre a aplicação deste nutriente pode ser feita a partir da avaliação do estado nutricional nitrogenado da planta. Essa avaliação pode ser feita por diversos procedimentos e análises que fornecem índices de $\mathrm{N}$ na planta (Fontes, 2001, 2011).

Em condições de campo, o parcelamento do adubo nitrogenado é um método comumente proposto para melhorar a eficiência do uso do N, principalmente pela redução na probabilidade de perdas por lixiviação. O efeito do parcelamento da adubação nitrogenada na batateira foi avaliado por Maidl et al. (2002), os quais verificaram que a recuperação do $\mathrm{N}$ do fertilizante foi, em média, 33 ou $44 \%$ quando toda a dose foi aplicada no momento do plantio ou parcelada em três vezes, respectivamente. Comparada à aplicação de toda a dose no plantio, o parcelamento da dose de $\mathrm{NH}_{4} \mathrm{NO}_{3}$ na cultura da batata diminuiu ou não a emissão de $\mathrm{N}_{2} \mathrm{O}$, dependendo do ano (Burton et al., 2008).

Relatos sobre a eficiência do parcelamento da dose de $\mathrm{N}$ em condição de campo são numerosos e com resultados contraditórios, indicando que pode haver benefícios sobre a produtividade com a prática de parcelar o adubo (Errebhi et al., 1998; Chowdhury et al., 2002), mas pode não haver benefícios ou mesmo haver prejuízos na cultura da batata (Joern \& Vitosh, 1995; Vos, 1999; Kuisma, 2002; Zebarth et al., 2004; Love et al., 2005). Contudo, resultados experimentais sobre o parcelamento da dose de $\mathrm{N}$ em condições de vaso objetivando a produção de mini-tubérculos, na cultura da batata não são comuns na literatura.

O objetivo do trabalho foi avaliar a produção de mini-tubérculos de batata semente básica, cultivares Atlantic e Opaline, em função da dose e do parcelamento do nitrogênio aplicado ao substrato.

\section{MATERIAL E MÉTODOS}

$\mathrm{O}$ experimento foi realizado no Departamento de Fitotecnia da Universidade Federal de Viçosa, de 20/09 a 22/12/2010, em ambiente protegido, modelo tipo capela, coberta com polietileno e provida de ventilação lateral. Foram plantadas as cultivares Atlantic e Opaline. O mini-tubérculo semente da categoria básica, devidamente uniformizado e brotado naturalmente, foi utilizado como material de propagação, adquirido de firma comercial produtora de semente.

$\mathrm{O}$ experimento foi instalado no delineamento de blocos casualizados, em esquema fatorial $4 \times 5$, com três repetições. Os tratamentos foram constituídos pela combinação de quatro doses de $\mathrm{N}$ $\left(0,115,230,460 \mathrm{mg} \mathrm{L}^{-1}\right.$ de substrato) e por cinco modos de parcelamento das doses (M): M1 [10\% no plantio $+90 \%$ aos 21 dias após a emergência (DAE)]; M2 [10\% no plantio $+3 \%$ diariamente (21 a 51 DAE)]; M3 [50\% no plantio + $50 \%$ aos $21 \mathrm{DAE}$ ]; M4 [50\% no plantio $+1,6 \%$ diariamente (21 a 51 DAE)]; M5 ( $100 \%$ no plantio).

Cada parcela experimental foi constituída de um vaso contendo uma planta. A dose de $\mathrm{N}$ foi misturada ao substrato no plantio e em cobertura por meio de fertirrigação diária. A fonte de $\mathrm{N}$ usada foi o nitrato de amônio $\left[\mathrm{NH}_{4} \mathrm{NO}_{3}(32 \%\right.$ N)].

No momento do plantio, além das doses diferenciadas de $\mathrm{N}$ aplicadas ao substrato, foram adicionadas doses dos demais fertilizantes. A quantidade $\left(\mathrm{mg} \mathrm{dm}^{-3}\right)$ de fertilizantes aplicada e misturada ao substrato antes do plantio foi: 3.380 de super simples; 3.600 de sulfato de magnésio; 132 de cloreto de potássio; 2,5 de ácido bórico; 2,5 de sulfato de zinco; 2,5 de sulfato de cobre; 2,5 de sulfato ferroso; 2,5 de sulfato manganoso e 0,25 de molibdato de sódio. Adicionalmente, aos $21 \mathrm{DAE}$, foi aplicado $1.320 \mathrm{mg} \mathrm{dm}^{-3}$ de cloreto de potássio em cobertura. Os fertilizantes foram incorporados ao substrato, em pré-plantio, exceto o cloreto de potássio que foi aplicado $10 \%$ em pré-plantio e $90 \%$ em cobertura, aos 21 DAE.

Foi utilizado o substrato comercial Tropstrato ${ }^{\circledR}$ HT Hortaliças. Segundo o fabricante, o substrato tem a base de casca de pinus, turfa, vermiculita expandida, enriquecido com macro e micronutrientes, sem especificação granulométrica e apresenta a densidade de $490 \mathrm{~kg} \mathrm{~m}^{-3}$, capacidade de retenção de água de $130 \%(\mathrm{p} / \mathrm{p}), \mathrm{pH}$ em torno de 6,0 e condutividade elétrica de $0,5 \mu \mathrm{S}$ $\mathrm{cm}^{-1}$ no extrato aquoso 5:1. O substrato apresentou $0,62 \%$ de $\mathrm{N}$, determinado no extrato ácido (sulfúrico) pelo método Kjeldahl.

Os mini-tubérculos foram plantados em vaso de $3 \mathrm{~L}$ contendo o substrato comercial. Aos 21 dias após a emergência (DAE) foi realizada a aplicação de quantidade adicional de substrato na parte superior do vaso, imitando-se a amontoa que é feita normalmente no campo.

Aos 21, 35 e 56 DAE foi coletada a quarta folha a partir do ápice (folha referência). Após a secagem, a folha referência foi macerada em cadinho, para a determinação do teor de $\mathrm{N}(\mathrm{TN})$, após digestão sulfúrica, utilizando-se o reagente Nessler (Jackson, 1958). Pela multiplicação da massa seca da folha referência pelo teor de $\mathrm{N}$ foi obtida a variável conteúdo de $\mathrm{N}$ ou quantidade de $\mathrm{N}$ acumulada na folha referência (QNA).

Durante o ciclo vegetativo os vasos foram irrigados diariamente com água deionizada. Após a completa seca natural da parte aérea, aos $86 \mathrm{DAE}$, foi realizada a colheita sendo avaliados os dados de produção: número de tubérculos (NT) e massas fresca (MFT) e seca de tubérculos (MST).

Os dados foram submetidos à análise de variância, de regressão, teste de média e de correlação, de acordo com a característica dos dados. Os modelos foram escolhidos com base na lógica biológica, significância dos coeficientes de regressão, utilizando-se o teste $\mathrm{t}$ a 1 e $5 \%$ de probabilidade e no coeficiente de determinação.

\section{RESULTADOS E DISCUSSÃO}

Em ambas as cultivares, na fase inicial de crescimento da planta, aos 21 DAE, nenhuma combinação de tratamentos (dose e modo) influenciou o teor de $\mathrm{N}(\mathrm{TN})$ na folha referência (Tabela 1). Provavelmente, até então a disponibilidade de $\mathrm{N}$ no substrato não foi fator limitante. Aos 56 DAE passou a ser observado o efeito de dose, em cada modo de aplicação, sobre o TN, 
Tabela 1. Valor médio do teor de nitrogênio $(\mathrm{TN})$ e da quantidade de nitrogênio acumulada na folha referência, em cada modo de aplicação (M) do nitrogênio ao substrato, respectivamente aos 21, 35 e 56 dias após a emergência das plantas, para as cultivares de batata Atlantic e Opaline [average value of the nitrogen content (TN) and the amount of nitrogen accumulated in the reference leaf in each application mode (M) of nitrogen to the substrate, respectively at 21, 35 and 56 days after plant emergence, potato cultivars Atlantic and Opaline]. Viçosa, UFV, 2010.

\begin{tabular}{|c|c|c|c|c|c|c|}
\hline \multirow{3}{*}{ Característica } & \multicolumn{6}{|c|}{ Dias após a emergência } \\
\hline & \multicolumn{2}{|c|}{21} & \multicolumn{2}{|c|}{35} & \multicolumn{2}{|c|}{56} \\
\hline & Atlantic & Opaline & Atlantic & Opaline & Atlantic & Opaline \\
\hline & \multicolumn{6}{|c|}{ Nitrogênio na folha referência $(\mathrm{g} / \mathrm{kg})$} \\
\hline TN-M1 & 77,00 & 75,31 & S & 56,79 & $\mathrm{~S}$ & 55,83 \\
\hline TN-M2 & 75,38 & 78,56 & S & 59,02 & $\mathrm{~S}$ & $\mathrm{~S}$ \\
\hline TN-M3 & 75,73 & 73,24 & S & 57,15 & $\mathrm{~S}$ & S \\
\hline TN-M4 & 75,29 & 73,60 & 63,53 & 57,87 & $\mathrm{~S}$ & $\mathrm{~S}$ \\
\hline \multirow[t]{2}{*}{ TN-M5 } & 76,27 & 66,51 & $\mathrm{~S}$ & 56,36 & 43,88 & 56,20 \\
\hline & \multicolumn{6}{|c|}{ Nitrogênio acumulado na folha referência (mg) } \\
\hline QNA-M1 & 13,79 & 5,92 & 39,91 & 11,06 & 39,95 & 10,66 \\
\hline QNA-M2 & 16,10 & 7,20 & 41,91 & 11,34 & 38,20 & 10,73 \\
\hline QNA-M3 & 16,54 & 6,17 & $\mathrm{~S}$ & 9,48 & $\mathrm{~S}$ & 8,66 \\
\hline QNA-M4 & 14,50 & 6,37 & 40,48 & 11,61 & 36,64 & 10,54 \\
\hline QNA-M5 & $\mathrm{S}$ & 5,19 & 41,89 & 12,05 & $\mathrm{~S}$ & $\mathrm{~S}$ \\
\hline
\end{tabular}

$\mathrm{S}=$ houve efeito significativo de dose de $\mathrm{N}$; QNA= quantidade de $\mathrm{N}$ na folha ( $\mathrm{S}=$ significant effect of $\mathrm{N}$ doses; QNA= $\mathrm{N}$ quantity on leaf).

Tabela 2. Relação entre dose de nitrogênio (X, expresso em $\mathrm{mg} \mathrm{dm}^{-3}$ ) e o teor de nitrogênio na massa seca da folha referência (TN) (Y, expresso em $\mathrm{g} \mathrm{kg}^{-1}$ ) e entre a quantidade de $\mathrm{N}$ acumulada na folha referência (QNA) (Y, expresso em $\mathrm{mg}$ ), em cada modo de aplicação (M) do nitrogênio ao substrato, respectivamente aos 21,35 e 56 dias após a emergência das plantas para as cultivares de batata Atlantic e Opaline [relation between nitrogen (X, expressed in $\mathrm{mg} \mathrm{dm}^{-3}$ ) and total nitrogen in the dry leaf reference (TN) (Y, expressed in $\left.\mathrm{g} \mathrm{kg}^{-1}\right)$ and between the amount of $\mathrm{N}$ accumulated in the reference leaf (QNA) (Y, expressed in $\mathrm{mg}$ ) in each application mode (M) of nitrogen to the substrate, respectively at 21, 35 and 56 days after plant emergence, potato cultivars Atlantic and Opaline]. Viçosa, UFV, 2010.

\begin{tabular}{|c|c|c|}
\hline \multicolumn{3}{|c|}{ Atlantic } \\
\hline TN35-M1 & $\hat{\mathrm{y}}=60,8327+0,02785 * x$ & 0,95 \\
\hline TN35-M2 & $\hat{\mathrm{y}}=60,9840+0,01838 * * \mathrm{X}$ & 0,92 \\
\hline TN35-M3 & $\hat{y}=62,7327+0,01447 * x$ & 0,93 \\
\hline TN35-M5 & $\hat{\mathrm{y}}=60,5583+0,06482 * \mathrm{X}-0,00011316^{*} \mathrm{X}^{2}$ & 0,97 \\
\hline TN56-M1 & $\hat{y}=40,9093+0,03300 * * x$ & 0,99 \\
\hline TN56-M2 & $\hat{\mathrm{y}}=41,7747+0,03977 * x$ & 0,97 \\
\hline TN56-M3 & $\hat{y}=42,1567+0,02333 * x$ & 0,80 \\
\hline TN56-M4 & $\hat{y}=42,1080+0,02581 * x$ & 0,97 \\
\hline QNA21-M5 & $\hat{\mathrm{y}}=21,40235-0,06005 * * \mathrm{X}+0,00009547^{*} \mathrm{X}^{2}$ & 0,80 \\
\hline QNA35-M3 & $\hat{y}=46,66468-0,03280 * X$ & 0,67 \\
\hline QNA56-M3 & $\hat{\mathrm{y}}=30,57363+0,07084 * \mathrm{X}-0,00014077 * \mathrm{X} 2$ & 0,96 \\
\hline \multicolumn{3}{|c|}{ Opaline } \\
\hline TN56-M2 & $\hat{y}=50,12215+0,11512 * X-0,00021134 * X^{2}$ & 0,98 \\
\hline TN56-M3 & $\hat{y}=51,40667+0,02636 * x$ & 0,85 \\
\hline TN56-M4 & $\hat{y}=46,17667+0,04716^{*} x$ & 0,86 \\
\hline QNA56-M5 & $\hat{y}=5,33388+0,02665^{*} X$ & 0,93 \\
\hline
\end{tabular}

havendo aumento de TN com aumento da dose de $\mathrm{N}$ (Tabela 2). O produto de TN pela massa seca da folha fornece a quantidade de nitrogênio na folha referência (QNA); portanto, um índice que associa o desenvolvimento da planta a seu estado nitrogenado. Verificou-se, nas duas cultivares, que tal índice não foi afetado por dose de $\mathrm{N}$ quando essa foi aplicada diluidamente como em M2 e M4 (Tabela 1).

$\mathrm{O}$ aumento do teor de $\mathrm{N}$ na folha referência (TN) verificado nos diversos modos de aplicação e épocas de amostragem causadas pelos tratamentos (Tabela 2) não propiciou reflexo no número total de tubérculos (NT). Nenhuma combinação de modo de aplicação do fertilizante nitrogenado e dose de $\mathrm{N}$ influenciaram o NT, o qual atingiu o valor médio estimado em unidades por planta de 4,75 e 28,63 para as cultivares Atlantic e Opaline, respectivamente (Tabela 3). A diferença observada no número de tubérculos é devida às características intrínsecas das cultivares.

Dose de $\mathrm{N}$ aplicada em maior proporção na fase de inicio de tuberização, 21 DAE, como ocorreu em M1 e M3, principalmente na cultivar Atlantic, 
Tabela 3. Equações ajustadas para a relação entre dose de nitrogênio (X, expresso em $\mathrm{mg} \mathrm{dm}^{-3}$ ) e o número de tubérculos (NT expresso em unidade), massa fresca total de tubérculos (MFT, expressa em g) e massa seca total de tubérculos (MST, expressa em g), em cada modo de aplicação (M) do nitrogênio ao substrato, respectivamente aos 21, 35 e 56 dias após a emergência das plantas, para as cultivares de batata Atlantic e Opaline [adjusted equations for the relation between nitrogen (X, expressed in $\mathrm{mg} \mathrm{dm}^{-3}$ ) and the number of tubers (NT expressed in unit), total fresh tuber (MFT, expressed in g) and total dry mass of tubers (MST expressed in grams) in each application mode (M) of nitrogen to the substrate, respectively at 21, 35 and 56 days after plant emergence, potato cultivars Atlantic and Opaline]. Viçosa, UFV, 2010.

\begin{tabular}{|c|c|c|}
\hline \multirow{2}{*}{ Variável } & Equação ajustada & $\mathbf{r}^{2} / \mathbf{R}^{2}$ \\
\hline & \multicolumn{2}{|c|}{ Atlantic } \\
\hline NT-M1 & $\hat{y}=4,8333$ & - \\
\hline NT-M2 & $\hat{y}=4,7500$ & - \\
\hline NT-M3 & $\hat{y}=4,9167$ & - \\
\hline NT-M4 & $\hat{y}=5,5000$ & - \\
\hline NT-M5 & $\hat{y}=3,7250$ & - \\
\hline MFT-M1 & $\hat{\mathrm{y}}=171,6667-0,09607 * \mathrm{X}$ & 0,78 \\
\hline MFT-M2 & $\hat{y}=163,0833$ & - \\
\hline MFT-M3 & $\hat{\mathrm{y}}=161,9333-0,09449 * \mathrm{X}$ & 0,96 \\
\hline MFT-M4 & $\hat{y}=166,2500$ & - \\
\hline MFT-M5 & $\hat{y}=152,1668$ & - \\
\hline MST-M1 & $\hat{y}=26,9927-0,01327^{*} X$ & 0,40 \\
\hline MST-M2 & $\hat{y}=27,4317$ & - \\
\hline MST-M3 & $\hat{y}=26,3858-0,01774 * x$ & 0,66 \\
\hline MST-M4 & $\hat{y}=25,7337$ & - \\
\hline \multirow[t]{2}{*}{ MST-M5 } & $\hat{y}=24,3467$ & - \\
\hline & \multicolumn{2}{|c|}{ Opaline } \\
\hline NT-M1 & $\hat{y}=25,9167$ & - \\
\hline NT-M2 & $\hat{y}=32,0833$ & - \\
\hline NT-M3 & $\hat{y}=31,5000$ & - \\
\hline NT-M4 & $\hat{y}=28,2500$ & - \\
\hline NT-M5 & $\hat{y}=25,4167$ & - \\
\hline MFT-M1 & $\hat{y}=160,5000$ & - \\
\hline MFT-M2 & $\hat{\mathrm{y}}=185,5000$ & - \\
\hline MFT-M3 & $\hat{y}=179,5000$ & - \\
\hline MFT-M4 & $\hat{y}=166,5000$ & - \\
\hline MFT-M5 & $\hat{y}=148,6667$ & - \\
\hline MST-M1 & $\hat{y}=19,37158$ & - \\
\hline MST-M2 & $\hat{y}=22,85792$ & - \\
\hline MST-M3 & $\hat{y}=21,67883$ & - \\
\hline MST-M4 & $\hat{y}=19,96400$ & - \\
\hline MST-M5 & $\hat{y}=16,83083$ & - \\
\hline
\end{tabular}

*significativo a 5\% de probabilidade pelo teste "t" (significant at 5\% probability, "t" test).

promoveu efeito linear decrescente nas variáveis massas fresca (MFT) e seca de tubérculo (MST), determinadas na colheita (Tabela 3). Nos demais modos de aplicação, 2, 4 e 5, não houve efeito de dose sobre as referidas variáveis.

A aplicação concentrada de N, 90 e $50 \%$ da dose estudada, aos 21 DAE (modo de aplicação 1 e 3) para a cultivar Atlantic e 90\% da dose estudada, aos 21 DAE (modo de aplicação 1) para a cultivar Opaline, provocou efeito negativo sobre a produção de tubérculos (massa). Nessa data, as doses de 115, 230 e 460 $\mathrm{mg} \mathrm{dm}{ }^{-3}$ foram integralizadas nos modos de aplicação 1 e 3, enquanto já haviam sido integralizadas no momento do plantio no modo 5 de aplicação, visto que não houve efeito de dose de $\mathrm{N}$ sobre a produção de tubérculos. Desta forma, o efeito negativo de dose de $\mathrm{N}$ sobre a produção (massa) de tubérculos de batata foi devido ao modo de aplicar e não devido à dose de $\mathrm{N}$ aplicada.

Nos modos de aplicação 1 e 3 (90 e $50 \%$ ) foi elevada a porcentagem de cada dose aplicada de uma única vez em cobertura aos 21 DAE. É nessa ocasião que se inicia o processo de tuberização, com elevada taxa de enchimento de tubérculos. Pode ser que o processo de enchimento de tubérculos tenha sido irreversivelmente influenciado pela aplicação do $\mathrm{N}$, resultando em efeito linear decrescente das doses de $\mathrm{N}$ sobre a produção (massa) de tubérculos na colheita, sem contudo terem as mesmas doses influenciado a diferenciação do NT.

A adição de $\mathrm{N}$ a substrato orgânico com alta disponibilidade de $\mathrm{N}$ pode proporcionar efeito negativo sobre a produção de tubérculo-semente, principalmente em vaso. Tal fato foi relatado por Fontes et al. (2008) ao utilizarem plântula de batata advinda de cultura de tecido como material de propagação cultivada em substrato orgânico. Em campo de produção no sistema orgânico, Hagman et al. (2009) encontraram que a adição de $\mathrm{N}$ não teve efeito significativo sobre a produção de tubérculos de batata.

Extensivos estudos têm mostrado que a tuberização da batata é controlada por diversos fatores ambientais e endógenos na planta tais como temperatura, comprimento do dia, combinação de hormônios, disponibilidade de nutrientes incluindo-se o N. Portanto, o N é fator ambiental envolvido no controle da tuberização que, juntamente com o fotoperíodo, pode permitir a tuberização por meio dos fitohormônios endógenos (Jackson, 1999). Alto nível de $\mathrm{N}$ pode inibir a atividade ou alterar os níveis de reguladores de crescimento na planta (Stallknecht, 1985). Em condições de campo, doses consideradas elevadas de $\mathrm{N}$ atrasam a tuberização (Santelith \& Ewing, 1981), reduzem a translocação do carbono da folha para os tubérculos 
e aumentam o fluxo de $\mathrm{N}$ para as folhas novas ao invés de dirigi-lo aos tubérculos (Oparka et al., 1987).

Em condição de campo, os relatos sobre os efeitos do parcelamento da dose de $\mathrm{N}$ são numerosos e com resultados variáveis, indicando que pode haver benefícios sobre a produtividade com a prática de parcelar o adubo (Errebhi et al., 1998; Chowdhury et al., 2002), mas pode não haver benefícios ou mesmo haver prejuízos na cultura da batata (Joern \& Vitosh, 1995; Vos, 1999; Kuisma, 2002; Zebarth et al., 2004; Love et al., 2005). As diferenças de respostas ao parcelamento da dose de $\mathrm{N}$ em condição de campo são determinadas por fatores como textura do solo, intensidade de chuva, rapidez de formação do sistema radicular, teor de $\mathrm{N}$ disponível no solo, dose adicionada do adubo nitrogenado entre outras que aumentem a probabilidade de lixiviação e de salinização do meio.

Em condições de alto suprimento de $\mathrm{N}$ e, mais frequentemente, sob condições de pouca luz, a planta tende a acumular $\mathrm{N}$ nas folhas como resultado do excesso de absorção (consumo de luxo) em relação à incorporação (Demsar et al., 2004). $\mathrm{O}$ excesso de $\mathrm{N}$ regula a biosíntese de carboidratos. Isso pode ter ocorrido no presente experimento, em ambiente protegido e com temperatura relativamente alta durante a fase experimental, em que a máxima variou de $30-35^{\circ} \mathrm{C}$ e a mínima de $19-23^{\circ} \mathrm{C}$. Nessas condições, a adição de $\mathrm{N}$ ao substrato orgânico pode ter sido maior do que a incorporação de carbono por limitação no suprimento de energia luminosa e alta respiração.

Nenhuma combinação de dose e modo de aplicação do fertilizante nitrogenado influenciou o número de tubérculos de batata. Além disso, quando houve efeito de dose de N sobre a massa de tubérculos, a dose zero proporcionou o maior valor da massa. A aplicação concentrada de $\mathrm{N}$ no momento da tuberização foi prejudicial para a planta, pois reduziu a massa seca e fresca de tubérculos.

\section{AGRADECIMENTOS}

Os autores agradecem à FAPEMIG,
CAPES e ao CNPq pelo apoio financeiro e concessão de bolsas de pós-graduação.

\section{REFERÊNCIAS}

AGRIANUAL. 2011. Anuário da Agricultura Brasileira. São Paulo: FNP Consultoria e Agroinformativos.

BURTON DL; ZEBARTH BJ; GILLAM KM; MACLEOD JA. 2008. Effect of split application of fertilizer nitrogen on $\mathrm{N}_{2} \mathrm{O}$ emissions from potatoes. Canadian Journal of Soil Science 88: 229-239.

CHOWDHURY MRI; SARWAR AKMG; FAROOQUE AM. 2002. Effect of nitrogen and its methods of application on growth and yield of potato. Journal of Biological Sciences 2: 616-619.

COELHO FS; FONTES PCR; PUIATTI M; NEVES JCL; SILVA MCC. 2010. Dose de N associada à produtividade de batata e índices do estado de N na folha. Revista Brasileira de Ciência do Solo 34: 1175-1183.

CORASPE-LEON HM. 2007. Aspectos nutricionais da batateira para a produção de tubérculo-semente em ambiente protegido. Piracicaba: ESALQ, 111p (Tese doutorado).

DEMSAR J; OSVALD J; VODNIK D. 2004 The effect of light-dependent application of nitrate on the growth of aeroponically grown lettuce (Lactuca sativa L.). Journal of the American Society for Horticultural Science 129: 570-575.

ERREBHI M; ROSEN CJ; GUPTA SC; BIRONG DE. 1998. Potato yield response and nitrate leaching as influenced by nitrogen management. Agronomy Journal 90: 10-15.

FONTES PCR. 2001. Diagnóstico do estado nutricional das plantas. Viçosa: Universidade Federal de Viçosa, 122p.

FONTES PCR. 2011. Nutrição mineral de plantas: avaliação e diagnose. Viçosa: Editora Arka, 296p.

FONTES PCR; SAMPAIO JUNIOR JD; MOREIRA MA; GUIMARÃES MA; PUIATTI M; LANI ERG. 2008. Produção de mini-tubérculos de batata-semente em função de doses de $\mathrm{N}$ aplicadas ao substrato. Horticultura Brasileira 26: 116-120.

HAGMAN JE; MARTENSSONA; GRANDIN U. 2009. Cultivation practices and potato cultivars suitable for organic potato production. Potato Research 52: 319-330.

JACKSON ML. 1958. Soil chemical analysis. Englewood Cliffs: Prentice Hall.

JACKSON SD. 1999. Multiple signaling pathways control tuber induction in potato. Plant Physiology 119: 1-8.

JOERN BC; VITOSH ML. 1995. Influence of applied nitrogen on potato part i: yield, quality, and nitrogen uptake. American Potato Journal 72: 51-73.

KUISMA P. 2002. Efficiency of split nitrogen fertilization with adjusted irrigation on potato. Agricultural and Food Science in Finland 11: 59-74.

LOVE SL; STARK JC; SALAIZ T. 2005.
Response of four potato cultivars to rate and timing of nitrogen fertilizer. American Journal of Potato Research 82: 21-30.

MAIDL FX; BRUNNER H; STICKSEL E. 2002. Potato uptake and recovery of nitrogen $15 \mathrm{~N}$-enriched ammonium nitrate. Geoderma 105: 167-177.

MOREIRA MA. 2008. Características da planta e produção de batata-semente básica em substrato com diferentes materiais de propagação Viçosa: UFV, 190p. (Tese doutorado).

NAVA G; DECHEN AR; IUCHI VL. 2007. Produção de tubérculos de batata-semente em função das adubações nitrogenada, fosfatada e potássica. Horticultura Brasileira 25: 365-370.

OPARKA KJ; DAVIES HV; PRIOR DAM. 1987. The influence of applied $N$ on export and partitioning of current assimilate by field grown potato plants. Annals of Botany 59: 484-488.

SAMPAIO JUNIOR JD; FONTES PCR; GUIMARÃES MA; MOREIRA MA. 2009. Produção de mini-tubérculos de batata propagadas por brotos, em função de doses de $\mathrm{N}$ aplicadas ao substrato. Bioscience Journal 25: 75-82.

SAMPAIO JUNIOR JD; FONTES PCR; MOREIRA MA; GUIMARÃES MA. 2008. Produção de mini-tubérculo semente de batata, em função de doses de $\mathrm{N}$ aplicadas ao substrato. Bioscience Journal 24: 1-9.

SANTELITH G; EWING EE. 1981. Effects of nitrogen fertilization on growth and development of potatoes. Americam Potato Journal 58: 517-518.

SILVA EC; GIUSTO AB; DIAS JACS. 2006. Produção de mini-tubérculos a partir de brotos de cultivares de batata em diferentes combinações de substratos. Horticultura Brasileira 24: 241-244.

SILVA MCC; FONTES PCR; MIRANDA GV. 2007. Modelos estatísticos para descrever a produtividade de batata em função da adubação nitrogenada. Horticultura Brasileira 25: 360-364.

STALLKNECHT GF. 1985. Tuber initiation in Solanum tuberosum: effect of phytohormones and induced changes in nucleic acid and protein metabolism. In: LI PH. Potato Physiology. London: Academic Press, p. 231- 260 .

VOS J. 1999. Split nitrogen application in potato: Effects on accumulation of nitrogen and dry matter in the crop and on the soil nitrogen budget. Journal of Agricultural Science 133: 263-274.

ZEBARTH BJ; LECLERC Y; MOREATL G. 2004. Rate and timing of nitrogen fertilization of Russet Burbank potato: nitrogen use efficiency. Canadian Journal Plant Science 84: 845-854.

ZVOMUYA F; ROSEN CJ; RUSSELLE MP; GUPTA SC. 2003. Nitrate leaching and nitrogen recovery following application of polyolefin-coated urea to potato-ground water quality. Journal of Environmental Quality 32: 480-489. 